\title{
Uso de Probiótico e Antibiótico sobre o Desempenho, o Rendimento e a Qualidade de Carcaça de Frangos de Corte $^{1}$
}

\author{
Maria Marta Loddi ${ }^{2}$, Elisabeth Gonzales ${ }^{3}$, Tânia Sayuri Takita ${ }^{4}$, Ariel Antônio Mendes ${ }^{3}$, \\ Roberto de Oliveira Roça ${ }^{3}$
}

RESUMO - Dois mil e quatrocentos pintos de corte foram distribuídos em um delineamento inteiramente ao acaso, com esquema fatorial $2 \times 2 \times 2$ (sexo, com e sem probiótico, com e sem antibiótico), totalizando oito tratamentos e seis repetições com 50 aves cada uma. Independente da suplementação recebida, os machos sempre foram mais pesados que as fêmeas. Entretanto, a análise de desempenho apresentou maiores peso corporal e ganho de peso para os machos que receberam suplementação de antibiótico, quando comparados aos não-suplementados. Até 42 dias de idade, o uso do antibiótico determinou aumento do consumo de ração, mas não influiu nas demais características de desempenho. No período de 1 a 21 dias e 1 a 42 dias de idade, a suplementação com probiótico influenciou negativamente o peso corporal, ganho de peso e consumo de ração das aves. Houve interação probiótico x antibiótico para rendimento de carcaça das aves, obtendo-se maior rendimento de carcaça com o uso da associação dos produtos na ração. Nenhum dos produtos afetou o rendimento de partes (cabeça, pés, asas, perna, peito e dorso), o rendimento de vísceras (coração, fígado e vísceras não-comestíveis), gordura abdominal e características sensoriais (intensidade de aroma, aroma estranho, sabor, sabor estranho, maciez, suculência, preferência, cor característica e aparência geral) da carne de peito e pernas. No presente estudo, não foram encontrados efeitos benéficos da suplementação de probiótico para frangos de corte.

Palavras-chave: análise sensorial, avoparcina, carcaça, Enterococcus faecium, frango de corte, rendimento

\section{Effect of the Use of Probiotic and Antibiotic on the Performance, Yield and Carcass Quality of Broilers}

\begin{abstract}
Two thousand and four hundred broiler chicks were assigned to a completely randomized design in a $2 \times 2 \times 2$ (sex, with and without probiotic, with and without antibiotic) factorial arrangement, totalizing eight treatments and six replicates with 50 birds in each one. Independently of supplementation fed, the males were always heavier than the females. However, the analyses performance showed higher body weight and weight gain for males fed antibiotic when compared to the non supplemented. The use of antibiotic increased feed intake up to 42 days of age, but it did not affect the other characteristics. Probiotic supplementation negatively influenced the body weight, weight gain and feed intake of the broilers from either 1 to 21 or 1 to 42 days of age. There was a probiotic $\mathrm{x}$ antibiotic interaction for carcass yield of the broilers, and the highest carcass yield were obtained when the products were associated in the diet. Neither probiotic nor antibiotic affected cut-part yield (head, feet, wings, leg, breast and back), viscera yield (heart, liver and non edible viscera), abdominal fat and sensorial characteristics (intensity of aroma, stranger aroma, flavor, stranger flavor, tenderness, juiciness, acceptability, characteristic color and overall aspect) of breast and leg meats. No beneficial effects of the probiotic supplementation in broiler diets were observed in the present study.
\end{abstract}

Key Words: avoparcin, broiler, carcass, Enterococcus faecium, sensorial analysis, yield

\section{Introdução}

Na produção avícola, o principal objetivoé a obtenção de alta produtividade, aliada à qualidade dos produtos finais. Para isso, utilizam-se aditivos alimentares, como os antibióticos, com a função de promover o crescimento.

O uso indiscriminado dos antibióticos na alimentação animal desde o princípio da década de 50 pode ter resultado no desenvolvimento de populações bacterianas resistentes (FULLER, 1989), determinando desequilíbrio na simbiose entre o microbiota desejável e o animal (MULDER, 1991). Além disso, alguns grupos de consumidores apresentam restrição ao consumo de carnes de aves criadas com rações contendo antibióticos, em particular no mercado externo para o qual se destinam 12 a $14 \%$ da produção brasileira de carne de frangos de corte (TABELAS da Avicultura, 1995).

\footnotetext{
1 Pesquisa financiada pela FAPESP.

2 Zootecnista, Bolsista da CAPES. Rua Mato Grosso, 385, Maringá, PR. 86033-110. E.mail: mmloddi@ fcav.unesp.br

3 Professor da UNESP - Botucatu, SP. E.mail: elisa.gonzales@ uol.com.br

4 Zootecnista, Bolsista FAPESP.
} 
Torna-se evidente, portanto, a necessidade de estudos de produtos alternativos que possam substituir os antibióticos na alimentação animal, sem causar perdas de produtividade e qualidade dos produtos finais. Os prováveis substitutos promotores de crescimento devem manter as ações benéficas dos antibióticos e eliminar as indesejáveis, como a resistência bacteriana.

Uma alternativa seria o uso dos probióticos, os quais são produtos constituídos por microrganismos vivos ou suas $L$-forms (sem a parede celular). Uma vez introduzidos no organismo animal, podem colonizar o novo ambiente, promover melhor o equilíbrio da flora intestinal e a produção de enzimas digestivas e vitaminas do complexo B e estimular a imunidade da mucosa intestinal, protegendo-a contra toxinas pré-formadas por outros organismos (FULLER, 1989). O primeiro uso de probiótico foi como competidor de bactérias patogênicas e coccídias (exclusão competitiva) e, recentemente, tem sido utilizado como promotor de crescimento (TOURNUT, 1998).

O uso de probiótico como promotor de crescimento pode resultar em maior ganho de peso, melhor índice de conversão alimentar, maior rendimento de carcaça e melhor palatabilidade da carne de frangos de corte e perus, como relatam DILWORTH e DAY (1978), OWINGS et al. (1990), JENSEN e JENSEN (1992), BERTECHINI e HOSSAIN (1993), ENGLAND et al. (1996) e JIN et al. (1998). Entretanto, nem sempre são observados benefícios do seu uso (FULLER, 1989; BARROW, 1992; CAVAZZONI et al., 1993; e HENRIQUE et al., 1997), a não ser quando associados a antibióticos (JENSEN e JENSEN, 1992; BERTECHINI e HOSSAIN, 1993).

A eficácia do probiótico é estritamente dependente da quantidade e das caraterísticas das cepas do microrganismo utilizado na elaboração do aditivo alimentar. Muitas vezes os probióticos não produzem bons resultados, pois não utilizam microrganismos que atendam os requisitos para atuar como probiótico, como exemplo, sobreviver às condições adversas do trato gastrintestinal (ação da bile e dos sucos gástricos, pancreático e entéricos); não ser tóxico e/ou patogênico; ter capacidade antagonistas às bactérias intestinais indesejáveis; ser altamente viável e estável durante a estocagem, além de, comprovadamente, benéfico ao hospedeiro (JIN et al., 1997; TOURNUT, 1998). Deve-se também observar que alguns microrganismos que poderiam atuar como probióticos não resistem à ação de alguns antibióticos ou anticoccidianos utilizados nas rações das aves (JIN et al., 1997, 1998; TOURNUT, 1998). Portanto, é importante que se analisem os probióticos como produtos separados, da mesma maneira como é feita com os antibióticos (TOURNUT, 1998).

O objetivo principal deste experimento foi avaliar os efeitos do uso de probiótico, constituído do ingrediente ativo Enterococcus faecium $\left(1 \times 10^{10} \mathrm{CFU} / \mathrm{g}\right.$ de produto), e a associação deste com o antibiótico avoparcina, na alimentação de frangos de corte, avaliando-se o desempenho (peso, ganho de peso, consumo de ração, conversão alimentar) e a mortalidade, o rendimento de carcaça, carne de peito e de pernas e a análise sensorial da carne do peito e da perna.

\section{Material e Métodos}

Dois mil e quatrocentos pintos de corte de um dia da linhagem comercial Ross foram distribuídos em um delineamento inteiramente ao acaso com esquema fatorial $2 \times 2 \times 2$ (macho e fêmea, com e sem probiótico, com e sem antibiótico), oito tratamentos com seis repetições de 50 aves cada uma. $\mathrm{O}$ antibiótico utilizado foi a avoparcina nas dosagens de $15 \mathrm{e}$ $10 \mathrm{ppm}$, respectivamente, nas rações inicial e de crescimento; e o probiótico usado foi LBC ME $10^{\circledR}$, constituído do ingrediente ativo Enterococcus faecium Cernelle 68 (SF 68), com uma concentração de $1 \times 10^{10} \mathrm{CFU} / \mathrm{g}$ de produto, adicionando-se $40 \mathrm{~g} / \mathrm{t}$ de ração em todas as fases de criação.

O experimento foi realizado no galpão experimental da Faculdade de Medicina Veterinária e Zootecnia - UNESP, Campus de Botucatu, composto de 48 boxes com capacidade para 50 aves $\left(10,6\right.$ aves $\left./ \mathrm{m}^{2}\right)$ cada um, no período de 03 de outubro a 14 de novembro de 1997. Para o registro da temperatura e umidade relativa do ar no interior do galpão experimental, durante todo período experimental, foi utilizado um termohigrógrafo.

Cada boxe foi equipado com um comedouro inicial (com capacidade para $4 \mathrm{~kg}$ ), um definitivo (capacidade para $25 \mathrm{~kg}$ ), um bebedouro inicial (capacidade para 41 ), outro definitivo e um sistema de aquecimento composto por uma lâmpada infravermelha. A cama utilizada foi de maravalha (5 $\mathrm{cm}$ de espessura).

Para atender as exigências nutricionais das aves, o período de criação foi dividido em duas fases: inicial (1 a 21 dias) e crescimento (22 a 42 dias). A água e as rações, na forma farelada, foram fornecidas ad libitum. Em nenhuma das fases de 
1126 Rev. bras. zootec.

criação foi adicionado agente anticocciano ou qualquer outro produto que pudesse ter ação antibiótica. As composições percentual e calculada das rações experimentais encontram-se na Tabela 1 .

O desempenho das aves foi medido por intermédio do registro do peso inicial (um dia) e peso final, do ganho de peso, do consumo de ração e da conversão alimentar aos 21 e 42 dias. A mortalidade foi controlada diariamente.

Aos 42 dias de idade, foram separadas duas aves por repetição (12 aves por tratamento, 48 machos e 48 fêmeas, 96 aves no total), as quais foram identificadas por etiquetas plásticas numeradas, submetidas a um jejum de seis horas, pesadas e, em seguida, processadas, segundo os procedimentos normais de abate: atordoamento, sangria, depenagem e evisceração. As carcaças, sem pés, cabeça, pescoço, vísceras comestíveis e gordura abdominal, foram pesadas antes do resfriamento em chiller. Em seguida, procedeuse à extração de peito e pernas, os quais foram desossados, e a carne pesada sem pele. O rendimento de carcaça foi calculado em relação ao peso vivo antes do abate $[\% \mathrm{RC}=($ Peso Carcaça $\mathrm{x}$ 100)/Peso Vivo] e o rendimento de carne de peito e pernas, em função do peso da carcaça $[\% \mathrm{RP}=($ Peso Parte x 100)/Peso Carcaça $]$. Após a pesagem da carne, as amostras foram mantidas em congelador para posteriores análises sensoriais de carne do peito e das pernas (coxa+sobrecoxa) dos machos.

Foram realizadas as análises sensoriais das características intensidade de aroma, aroma estranho, sabor, sabor estranho, maciez, suculência, preferência, cor característica e aparência geral, utilizando-se oito provadores treinados (ROÇA e BONASSI, 1985), conforme o procedimento recomendado pelo INSTITUTE OF FOOD TECHNOLOGISTS (1981).

Os dados de desempenho, rendimento de carcaça e partes nobres, e a análise sensorial foram submetidos à análise de variância para um delineamento inteiramente ao acaso com esquema fatorial, utilizando-se o procedimento GLM do programa SAS (1989). Os dados percentuais de mortalidade foram transformados em $(\% / 100)^{0,5}$, segundo SNEDECOR e COCHRAN (1967), antes da análise de variância.
Tabela 1 - Composição percentual e valores nutricionais calculados das rações inicial e crescimento

Table 1 - Percent composition and calculated values of starter and growing diets

\begin{tabular}{|c|c|c|}
\hline $\begin{array}{l}\text { Ingredientes }(\%) \\
\text { Ingredients }\end{array}$ & $\begin{array}{l}\text { Inicial } \\
1 \text { a } 21 \text { dias }) \\
\text { Starter } \\
(1-21 \text { days })\end{array}$ & $\begin{array}{c}\text { Crescimento } \\
\text { (22 a } 42 \text { dias) } \\
\text { Growing } \\
(22-42 \text { days })\end{array}$ \\
\hline Milho, moído & 56,11 & 63,61 \\
\hline $\begin{array}{l}\text { Maize, ground } \\
\text { Farelo de soja } \\
\text { Sovbean meal }\end{array}$ & 36,97 & 29,44 \\
\hline $\begin{array}{l}\text { Óleo de soja } \\
\text { Soybean oil }\end{array}$ & 3,20 & 3,36 \\
\hline $\begin{array}{l}\text { Fosfato bicálcico } \\
\text { Dicalcium phosphate }\end{array}$ & 1,85 & 1,88 \\
\hline $\begin{array}{l}\text { Calcário calcítico } \\
\text { Limestone }\end{array}$ & 1,01 & 0,90 \\
\hline $\begin{array}{l}\text { Sal }(\mathrm{NaCl}) \\
\text { Salt }\end{array}$ & 0,35 & 0,35 \\
\hline $\begin{array}{l}\text { Suplemento vitamínico } \\
\text { Vitamin premix }^{1}\end{array}$ & 0,10 & 0,10 \\
\hline $\begin{array}{l}\text { Suplemento de microminerais } \\
\text { Micromineral premix }{ }^{2}\end{array}$ & is $^{2} 0,10$ & 0,10 \\
\hline $\begin{array}{l}\text { Cloreto de colina } \\
\text { Sodium choline }\end{array}$ & 0,08 & 0,06 \\
\hline $\begin{array}{l}\text { DL - Metionina } \\
\text { DL - Methionine }\end{array}$ & 0,23 & 0,20 \\
\hline Total & 100 & 100 \\
\hline $\begin{array}{l}\text { Composição calculada } \\
\text { Calculated composition } \\
\end{array}$ & & \\
\hline $\begin{array}{l}\mathrm{EM}(\mathrm{kcal} / \mathrm{kg}) \\
M E\end{array}$ & 3050 & 3150 \\
\hline $\begin{array}{l}\text { Proteína bruta (\%) } \\
\text { Crude protein }\end{array}$ & 21,000 & 19,060 \\
\hline $\begin{array}{l}\text { Metionina (\%) } \\
\text { Methionine }\end{array}$ & 0,570 & 0,458 \\
\hline $\begin{array}{l}\text { Met+cistina }(\%) \\
\text { Methionine + Cistine }\end{array}$ & 0,929 & 0,821 \\
\hline $\begin{array}{l}\text { Lisina }(\%) \\
\text { Lysine }\end{array}$ & 1,200 & 1,000 \\
\hline $\begin{array}{l}\text { Cálcio }(\%) \\
\text { Calcium }\end{array}$ & 0,960 & 0,900 \\
\hline $\begin{array}{l}\text { Fósforo disponível (\%) } \\
\text { Available phosphorus }\end{array}$ & 0,460 & 0,458 \\
\hline
\end{tabular}

1 NUTREMIX-Suplemento vitamínico (Vitamin premix). Composição por $\mathrm{kg}$ de produto (Composition per kg of product): Inicial: Vit. A, 10.500.00 UI; Vit. $D_{3}, 2.500 .000$ Ul; Vit. E, 15.000 mg; Vit. $K_{3}, 12.500$ mg; Vit. $B_{12}$, $19.000 \mathrm{mcg}$; Vit. $\mathrm{B}_{1}, 1000 \mathrm{mg}$; Vit. $\mathrm{B}_{2}, 7500 \mathrm{mg}$; Piridoxina (Piridoxine), $1250 \mathrm{mg}$; Biotina (Biotine), 100 mg; Ácido fólico (Folic acid), $450 \mathrm{mg}$; Pantotenato de cálcio (Pantotenic acid), 9500 mg; Niacina (Niacin), $40.000 \mathrm{mg}$; Antioxidante (Antioxidant), $50 \mathrm{mg}$.

Crescimento (Growing): Vit. A, $9.000 .00 \mathrm{UI}$; Vit. $\mathrm{D}_{3}, 2.000 .000 \mathrm{UI}$; Vit. E, $10.000 \mathrm{mg}$; Vit. $\mathrm{K}_{3}, 10.500 \mathrm{mg}$; Vit. $B_{12}, 18.000 \mathrm{mcg}$; Vit. $B_{1}, 800$ mg; Vit. $B_{2}, 6000$ mg; Piridoxina (Piridoxine), 1000 mg; Biotina (Biotine), $80 \mathrm{mg}$; Ácido fólico (Folic acid), $400 \mathrm{mg}$; Pantotenato de cálcio (Pantotenic acid), 8000 mg; Niacina (Niacin), 37.000 mg; Antioxidante (Antioxidant), $50 \mathrm{mg}$. 


\section{Resultados e Discussão}

Durante o período experimental, as médias, as mínimas e as máximas absolutas de temperatura e umidade relativa do ar, verificadas no interior do galpão experimental, foram $25,27 \pm 3,36^{\circ} \mathrm{C}, 16^{\circ} \mathrm{C}$, $37^{\circ} \mathrm{C} ; 65,4 \pm 12,25 \%, 26 \%$ e $99 \%$, respectivamente.

\section{Desempenho}

Os resultados de desempenho encontram-se nas Tabelas 2 e 3 . No período inicial, de 1 a 21 dias de idade, e no período total, de 1 a 42 dias de idade, não houve interação significativa entre os fatores estudados. Portanto, os fatores principais (antibiótico, probiótico e sexo) foram analisados separadamente.

Tanto para o período inicial (1-21 dias) quanto para o período total (1-42 dias), as diferenças entre sexo, superiores para os machos nas características de desempenho, corroboram vários trabalhos apresentados anteriormente (JIRAPHOCAKUL et al., 1990; OWINGS et al., 1990; e WOLKE et al., 1996).

Ao final do primeiro período experimental (1-21 dias), o peso final e o ganho de peso das aves suplementadas com antibiótico foram maiores $(\mathrm{P}<0,05)$ do que aqueles das aves que não receberam antibiótico. Para o período total de criação, de 1 a 42 dias de idade, somente o consumo de ração foi aumentado pelo uso da avoparcina $(\mathrm{P}<0,05)$, demostrando que o efeito benéfico do antibiótico no período experimental inicial não foi mantido para o período total de criação, concordando com os resultados obtidos por HENRIQUE et al. (1997). Entretanto, LESSON et al. (1980) e KRINKER E JAMORZ (1996) constataram melhora no ganho de peso e conversão alimentar dos frangos de corte que receberam avoparcina como promotor de crescimento durante todo o período de criação.

Independente dos fatores antibiótico e sexo, as aves suplementadas com probiótico apresentaram menores $(\mathrm{P}<0,05)$ peso final, ganho de peso e consumo de ração no período inicial de criação (primeiras três semanas), resultados estes que foram mantidos até o final da criação. A conversão alimentar não diferiu em nenhuma das fases de criação.

Resultados benéficos com o uso de probiótico, em todas as fases de criação, foram reportados por diferentes autores (DIRWORTH e DAY, 1978; OWINGS et al., 1990; e JIN et al., 1997), mas não por outros pesquisadores (JERIGAM e MILES, 1985; JIRAPHOCAKUL et al., 1990; KHAN et al., 1992; CAVAZZONI et al., 1993; WATKINS e KRATZER, 1984; e HENRIQUE et al., 1997), os quais encontraram resultados semelhantes aos observados neste experimento. Como a eficácia do produto é estritamente dependente da quantidade e das caraterísticas

Tabela 2 - Peso final (PF), ganho de peso (GP), consumo de ração (CR), conversão alimentar (CA) e mortalidade (Mort) de frangos de corte de 1 a 21 dias de idade, de acordo com o sexo e os tratamentos

Table 2 - Final weight (FW), weight gain (WG), feed intake (FI), feed:gain ratio (F/G) and mortality (Mort) of male and female broilers from 1 to 21 days of age fed probiotic and/or antibiotic

\begin{tabular}{|c|c|c|c|c|c|c|c|}
\hline \multirow{2}{*}{$\begin{array}{l}\text { Fatores } \\
\text { Treatments }\end{array}$} & & \multirow{2}{*}{$\begin{array}{c}\mathrm{PF}, \mathrm{g} \\
F W\end{array}$} & \multirow{2}{*}{$\begin{array}{c}\text { GP, g } \\
W G\end{array}$} & \multirow{2}{*}{$\begin{array}{c}\mathrm{CR}, \mathrm{g} \\
F I\end{array}$} & \multirow{2}{*}{$\begin{array}{l}\text { CA } \\
F / G\end{array}$} & \multicolumn{2}{|c|}{ Mort } \\
\hline & & & & & & $\%$ & Trans $^{1}$ \\
\hline \multirow{2}{*}{$\begin{array}{l}\text { Antibiótico } \\
\text { Antibiotic }\end{array}$} & Sem & $758,52^{\mathrm{b}}$ & $714,15^{\mathrm{b}}$ & 1052,27 & 1,48 & 1,96 & 0,14 \\
\hline & $\begin{array}{c}\text { Without } \\
\text { Com } \\
\text { With }\end{array}$ & $779,07^{\mathrm{a}}$ & $734,85^{\mathrm{a}}$ & 1065,95 & 1,45 & 1,96 & 0,14 \\
\hline \multirow{2}{*}{$\begin{array}{l}\text { Probiótico } \\
\text { Probiotic }\end{array}$} & Sem & $785,57^{a}$ & $741,40^{\mathrm{a}}$ & $1076,83^{\mathrm{a}}$ & 1,46 & 1,69 & 0,13 \\
\hline & $\begin{array}{c}\text { Without } \\
\text { Com } \\
\text { With }\end{array}$ & $752,01^{b}$ & $707,60^{\mathrm{b}}$ & $1041,39^{b}$ & 1,47 & 2,25 & 0,15 \\
\hline \multirow{2}{*}{$\begin{array}{l}\text { Sexo } \\
\text { Sex }\end{array}$} & Macho & $797,43^{a}$ & $753,21^{\mathrm{a}}$ & $1093,29^{a}$ & 1,46 & 2,56 & 0,16 \\
\hline & $\begin{array}{c}\text { Male } \\
\text { Fêmea } \\
\text { Female }\end{array}$ & $740,16^{\mathrm{b}}$ & $695,79^{\mathrm{b}}$ & $1024,93^{\mathrm{b}}$ & 1,48 & 1,44 & 0,12 \\
\hline$\overline{\mathrm{CV}(\%)}$ & & 1,90 & 2,03 & 2,98 & 3,05 & & 91,05 \\
\hline
\end{tabular}

10 percentual de mortalidade foi transformado em $(x / 100)^{0.5}$ antes da ANOVA.

Letras diferentes na mesma coluna, dentro de cada fator, diferem significativamente $(P<0,05)$.

1 Percent mortality transformed $(x / 100)^{0.5}$ before ANOVA.

Different letters in the same column are significantly different $(P<.05)$. 
1128 Rev. bras. zootec.

Tabela 3 - Peso final (PF), ganho de peso (GP), consumo de ração (CR), conversão alimentar (CA) e mortalidade (Mort) de frangos de corte machos e fêmeas alimentados com probiótico e/ou antibiótico de 1 a 42 dias de idade

Table 3 - Final weight (FW), weight gain (WG), feed intake (FI), feed:gain ratio (F/G) and mortality (Mort) of male and female broilers fed probiotic and/our antibiotic from 1 to 42 days of age

\begin{tabular}{|c|c|c|c|c|c|c|c|}
\hline \multicolumn{2}{|l|}{$\begin{array}{l}\text { Tratamentos } \\
\text { Treatments }\end{array}$} & \multirow[t]{2}{*}{$\begin{array}{c}\mathrm{PF}, \mathrm{g} \\
F W\end{array}$} & \multirow[t]{2}{*}{$\begin{array}{l}\mathrm{GP}, \mathrm{g} \\
W G\end{array}$} & \multirow[t]{2}{*}{$\begin{array}{l}\mathrm{CR}, \mathrm{g} \\
F I\end{array}$} & \multirow[t]{2}{*}{$\begin{array}{l}\mathrm{CA} \\
F / G\end{array}$} & \multicolumn{2}{|c|}{$\begin{array}{c}\text { Mortalidade } \\
\text { Mortalily }\end{array}$} \\
\hline & & & & & & $\%$ & Trans $^{1}$ \\
\hline \multirow{2}{*}{$\begin{array}{l}\text { Antibiótico } \\
\text { Antibiotic }\end{array}$} & Sem & 2123 & 2079 & $3813^{b}$ & 1,850 & 2,44 & 0,23 \\
\hline & $\begin{array}{c}\text { Without } \\
\text { Com } \\
\text { With }\end{array}$ & 2147 & 2103 & $3869^{\mathrm{a}}$ & 1,851 & 2,19 & 0,20 \\
\hline \multirow{2}{*}{$\begin{array}{l}\text { Probiótico } \\
\text { Probiotic }\end{array}$} & Sem & $2151^{\mathrm{a}}$ & $2107^{\mathrm{a}}$ & $3868^{a}$ & 1,848 & 2,30 & 0,21 \\
\hline & $\begin{array}{c}\text { Without } \\
\text { Com } \\
\text { With }\end{array}$ & $2119^{\mathrm{b}}$ & $2075^{\mathrm{b}}$ & $3815^{\mathrm{b}}$ & 1,854 & 2,33 & 0,22 \\
\hline \multirow{2}{*}{$\begin{array}{l}\text { Sexo } \\
\text { Sex }\end{array}$} & Macho & $2280^{\mathrm{a}}$ & $2235^{a}$ & $4076^{\mathrm{a}}$ & $1,839^{\mathrm{a}}$ & 2,83 & $0,28^{a}$ \\
\hline & $\begin{array}{c}\text { Male } \\
\text { Fêmea } \\
\text { Female } \\
\end{array}$ & $1990^{\mathrm{b}}$ & $1946^{\mathrm{b}}$ & $3607^{\mathrm{b}}$ & $1,863^{\mathrm{b}}$ & 1,81 & $0,16^{\mathrm{b}}$ \\
\hline$\overline{\mathrm{CV}(\%)}$ & & 2,01 & 2,05 & 2,21 & 1,880 & & 48,19 \\
\hline
\end{tabular}

das cepas do microrganismo utilizado na elaboração do probiótico (TOURNUT, 1998), é muito difícil estabelecer um paralelo entre estudos e comparar resultados.

O efeito sobre $(\mathrm{P}<0,05)$ o desempenho dos tratamentos que receberam suplementação do probiótico pode ser conseqüência da criação das aves em instalações novas, com ótimas condições profiláticas, não constituindo, portanto, uma situação de desafio. Assim, a microbiota intestinal teria se desequilibrado com a suplementação do Enterococcus faecium em quantidade acima da que normalmente é encontrada no trato digestório. Desse modo, o microrganismo que deveria promover o crescimento tornou-se um agente "infectante" e, provavelmente, deprimiu a metabolização e absorção dos nutrientes e, como conseqüência, o desempenho da ave. É necessário ser ressaltado que, quando o Enterococcus faecium foi utilizado como exclusor competitivo de uma cepa de Escherichia coli hemolítica, obtiveram-se resultados positivos sobre o desempenho dos frangos de corte (TOURNUT, 1998).

Rendimento de carcaça, partes e gordura abdominal

Observando-se a Tabela 4 , pode-se notar que houve interação significativa para rendimento de carcaça entre probiótico e antibiótico $(\mathrm{P}<0,05)$, obtendo-se rendimento maior, quando do uso do probiótico associado ao antibiótico $(\mathrm{P}<0,01)$. Dentro
Tabela 4 - Rendimento de carcaca (\%) de frangos de corte aos 42 dias de idade ${ }^{1}$

Table 4 - Carcass yield (\%) of broilers at 42 days of age ${ }^{1}$

\begin{tabular}{lcccc}
\hline Fatores & & \multicolumn{2}{c}{ Antibiótico } & \\
\cline { 3 - 4 } Treatments & & \multicolumn{2}{c}{ Antibiotic } & \multirow{2}{*}{ CV (\%) } \\
\cline { 2 - 4 } & & Without & Com & \\
\hline Probiótico & Sem & 69,12 & 68,58 & 2,05 \\
Probiotic & Without & & \\
& Com & $68,42^{\mathrm{b}}$ & $69,25^{\mathrm{a}}$ & \\
& With & & & \\
\hline
\end{tabular}

1 Carcaça eviscerada, sem pés, cabeça e pescoço. Rendimento $\%=$ (peso da carcaça/peso vivo) $\times 100$.

Letras diferentes na mesma linha diferem significativamente $(\mathrm{P}<0,10)$.

1 Eviscerated carcass without feet, head and neck. \% Yield = (carcass weight/ body weight) $x 100$.

Different letters in the same row are significantly different $(P<.10)$.

do fator sexo, evidenciou-se maior rendimento de carcaça para as fêmeas $(69,15 \%)$ em relação aos machos $(68,56 \%)$ (dados não apresentados).

Não houve interação $(\mathrm{P}<0,05)$ entre os fatores estudados para os rendimentos de cortes nobres e a porcentagem de gordura abdominal (Tabela 5). Para o fator antibiótico, não se observaram diferenças nas características das carcaças avaliadas $(\mathrm{P}<0,05)$.

Somente o rendimento de vísceras comestíveis 
LODDI et al.

1129

Tabela 5 - Rendimento de parte ${ }^{1}$, vísceras e gordura abdominal de frangos de corte aos 42 dias de idade Table 5 - Cut-up parts yield ${ }^{1}$, viscera and abdominal fat of broilers at 42 days of age

\begin{tabular}{|c|c|c|c|c|c|c|c|}
\hline \multirow[b]{2}{*}{$\begin{array}{l}\text { Características } \\
\text { Characteristics }\end{array}$} & \multicolumn{2}{|c|}{$\begin{array}{l}\text { Antibiótico } \\
\text { Antibiotic }\end{array}$} & \multicolumn{2}{|c|}{$\begin{array}{l}\text { Probiótico } \\
\text { Probiotic }\end{array}$} & \multicolumn{2}{|c|}{$\begin{array}{l}\text { Sexo } \\
\text { Sex }\end{array}$} & \multirow[b]{2}{*}{$\mathrm{CV}$} \\
\hline & $\begin{array}{c}\text { Sem } \\
\text { Without }\end{array}$ & $\begin{array}{l}\text { Com } \\
\text { With }\end{array}$ & $\begin{array}{c}\text { Sem } \\
\text { Without }\end{array}$ & $\begin{array}{l}\text { Com } \\
\text { With }\end{array}$ & $\begin{array}{l}\text { Macho } \\
\text { Male }\end{array}$ & $\begin{array}{l}\text { Fêmea } \\
\text { Female }\end{array}$ & \\
\hline & & & & & & & \\
\hline $\begin{array}{l}\text { Cabeça } \\
\text { Head }\end{array}$ & 9,13 & 9,33 & 9,22 & 9,23 & 9,29 & 9,17 & 10,29 \\
\hline Pés & 5,79 & 5,94 & 5,85 & 5,89 & $6,15^{\mathrm{a}}$ & $5,59^{\mathrm{b}}$ & 8,79 \\
\hline $\begin{array}{l}\text { Feet } \\
\text { Asas } \\
\text { Wings }\end{array}$ & 11,92 & 11,98 & 11,99 & 11,91 & $11,77^{b}$ & $12,13^{\mathrm{a}}$ & 5,29 \\
\hline $\begin{array}{l}\text { Perna com osso e pele } \\
\text { Leg with bone and skin }\end{array}$ & 33,04 & 33,29 & 33,18 & 33,15 & $33,54^{\mathrm{a}}$ & $32,79^{\mathrm{b}}$ & 4,09 \\
\hline $\begin{array}{l}\text { Carne da perna } \\
\text { Leg meat }\end{array}$ & 22,66 & 22,90 & 22,64 & 22,93 & $23,11^{\mathrm{a}}$ & $22,45^{b}$ & 6,16 \\
\hline $\begin{array}{l}\text { Osso da perna } \\
\text { Leg bone }\end{array}$ & 5,80 & 5,87 & 5,73 & 5,94 & 5,95 & 5,72 & 13,07 \\
\hline $\begin{array}{l}\text { Pele da perna } \\
\text { Leg skin }\end{array}$ & 3,78 & 3,79 & 3,88 & 3,69 & 3,70 & 3,86 & 16,18 \\
\hline $\begin{array}{l}\text { Peito c/ osso e pele } \\
\text { Breast with bone and skin }\end{array}$ & 33,32 & 32,99 & 33,15 & 33,16 & $32,81^{\mathrm{b}}$ & $33,50^{\mathrm{a}}$ & 4,18 \\
\hline $\begin{array}{l}\text { Carne de peito } \\
\text { Breast meat }\end{array}$ & 24,42 & 24,37 & 24,14 & 24,65 & $24,08^{\mathrm{b}}$ & $24,71^{\mathrm{a}}$ & 5,88 \\
\hline $\begin{array}{l}\text { Osso do peito } \\
\text { Breast bone }\end{array}$ & 4,16 & 4,11 & 4,13 & 4,15 & 4,10 & 4,17 & 12,87 \\
\hline $\begin{array}{l}\text { Pele do peito } \\
\text { Breast skin }\end{array}$ & 3,56 & 3,47 & 3,64 & 3,38 & 3,43 & 3,59 & 17,12 \\
\hline $\begin{array}{l}\text { Dorso } \\
\text { Back }\end{array}$ & 21,63 & 21,66 & 21,54 & 21,76 & 21,84 & 21,46 & 5,74 \\
\hline $\begin{array}{l}\text { Visc. não comest. } \\
\text { Non edible viscera }\end{array}$ & 8,48 & 8,08 & 8,37 & 8,19 & 8,53 & 8,04 & 14,06 \\
\hline $\begin{array}{l}\text { Visc. comest. totais } \\
\text { Edible viscera }\end{array}$ & 5,54 & 5,62 & $5,44^{\mathrm{b}}$ & $5,72^{\mathrm{a}}$ & 5,54 & 5,62 & 11,33 \\
\hline $\begin{array}{l}\text { Coração } \\
\text { Heart }\end{array}$ & 0,65 & 0,64 & 0,65 & 0,65 & 0,66 & 0,63 & 13,14 \\
\hline $\begin{array}{l}\text { Fígado } \\
\text { Liver }\end{array}$ & 3,08 & 3,13 & 3,06 & 3,15 & 3,11 & 3,11 & 15,71 \\
\hline $\begin{array}{l}\text { Moela } \\
\text { Gizzard }\end{array}$ & 1,87 & 1,84 & $1,79^{\mathrm{b}}$ & $1,94^{\mathrm{a}}$ & 1,84 & 1,88 & 13,26 \\
\hline $\begin{array}{l}\text { Gordura abdominal } \\
\text { Abdominal fat }\end{array}$ & 3,08 & 2,87 & 3,05 & 2,90 & $2,81^{b}$ & $3,15^{\mathrm{a}}$ & 24,41 \\
\hline
\end{tabular}

${ }^{1}$ Rendimento de parte $=$ (peso da parte/peso da carcaça) $\times 100$.

Letras diferentes na mesma linha, dentro de cada fator, diferem significativamente $(P<0,05)$.

1 Cut-up parts yield = (cut-up parts weight/carcass weight $) \times 100$.

Different letters in the same row are significantly different $(P<.05)$.

totais e moela foi afetado pelo uso de probiótico $(\mathrm{P}<0,05)$. O rendimento de partes, cortes nobres (com osso e sem osso), vísceras não-comestíveis, coração, fígado e gordura abdominal das aves suplementadas com probiótico não apresentaram diferença.

Resultados similares de rendimento de carcaça foram encontrados por MERKLEY (1985), OWINGS et al. (1990) e MOHAN et al. (1996). Já WATKINS e KRATZER (1984) observaram que os tratamentos com probiótico não apresentaram diferença no peso úmido e o peso seco do intestino delgado, enquanto
MOHAN et al. (1996) não verificaram diferenças de rendimento de coração, baço, fígado e moela. Com relação à gordura abdominal, o uso do probiótico propiciou diminuição de $5,1 \%$, não sendo, porém, detectada estatisticamente. Este resultado pode ser atribuído à ação lipolítica do produto, um dos seus mecanismos de ação, resultando em menor deposição de gordura no organismo da ave (MOHAN et al., 1996; JIN et al., 1998).

As diferenças entre sexo observadas para rendimento de partes, cortes nobres e gordura abdominal 
1130 Rev. bras. zootec.

são semelhantes ás de outros trabalhos apresentados anteriormente (FULLER, 1989; OWINGS et al., 1990).

\section{Análise sensorial}

Os resultados da análise sensorial da carne de peito e da carne de pernas estão apresentados na Tabela 6 .

Para a análise sensorial de carne de peito, observa-se que não houve efeito significativo entre os tratamentos. Para a carne de pernas, houve diferença significativa $(\mathrm{P}<0,05)$ nas características aroma estranho, sabor estranho e preferência no tratamento contendo associação de probiótico+antibiótico em relação aos tratamentos com adição de antibiótico e sem promotor de crescimento, mas não em comparação ao tratamento com adição de probiótico. Resultados parecidos foram obtidos por WILLIAMS e DAMRON (1998) para frangos de corte, quando usaram farinha

Tabela 6 - Resultado da análise sensorial de carne de peito e de pernas de frangos machos aos 42 dias de idade

Table 6 - Sensorial characteristics of meat breast and meat leg of male broiler at 42 days of age

\begin{tabular}{|c|c|c|c|c|}
\hline $\begin{array}{l}\text { Característica } \\
\text { Characteristics } \\
\end{array}$ & $\begin{array}{l}\text { Controle negativo } \\
\text { Negative control }\end{array}$ & $\begin{array}{c}\text { Probiótico } \\
\text { Probiotic }\end{array}$ & $\begin{array}{l}\text { Prob.+ Antib. } \\
\text { Prob. }+ \text { Antib. }\end{array}$ & $\begin{array}{c}\text { Antibiótico } \\
\text { Antibiotic }\end{array}$ \\
\hline \multicolumn{5}{|l|}{ Carne de peito } \\
\hline Breast meat & & & & \\
\hline $\begin{array}{l}\text { Intensidade aroma }{ }^{1} \\
\text { Intensity aroma }\end{array}$ & 6,71 & 6,50 & 6,60 & 6,44 \\
\hline Aroma estranho ${ }^{2}$ & 1,69 & 1,38 & 1,69 & 2,00 \\
\hline $\begin{array}{l}\text { Stranger aroma } \\
\text { Sabor }{ }^{1}\end{array}$ & 6,05 & 5,95 & 6,53 & 5,99 \\
\hline Flavor & & & & \\
\hline $\begin{array}{l}\text { Sabor estranho }{ }^{2} \\
\text { Strange flavor }\end{array}$ & 1,69 & 1,44 & 1,44 & 1,69 \\
\hline $\begin{array}{l}\text { Maciez }{ }^{1} \\
\text { Tenderness }\end{array}$ & 4,13 & 4,06 & 4,25 & 4,31 \\
\hline $\begin{array}{l}\text { Suculência } \\
\text { Juiciness }\end{array}$ & 5,06 & 4,94 & 4,87 & 4,37 \\
\hline $\begin{array}{l}\text { Preferência }{ }^{3} \\
\text { Acceptability }\end{array}$ & 2,25 & 2,13 & 2,50 & 2,56 \\
\hline $\begin{array}{l}\text { Cor característica }{ }^{1} \\
\text { Characteristic color }\end{array}$ & 7,04 & 6,91 & 6,70 & 6,74 \\
\hline $\begin{array}{l}\text { Aparência geral }{ }^{1} \\
\text { Overall aspect }\end{array}$ & 6,87 & 6,97 & 6,61 & 6,71 \\
\hline \multicolumn{5}{|l|}{ Carne de pernas } \\
\hline Leg meat & & & & \\
\hline $\begin{array}{l}\text { Aroma estranho }{ }^{2} \\
\text { Strange aroma }\end{array}$ & $1,33^{b}$ & $1,75^{\mathrm{ab}}$ & $2,75^{\mathrm{a}}$ & $1,25^{\mathrm{b}}$ \\
\hline $\begin{array}{l}\text { Sabor } \\
\text { Flavor }\end{array}$ & 6,59 & 6,37 & 6,13 & 6,80 \\
\hline $\begin{array}{l}\text { Sabor estranho }{ }^{2} \\
\text { Strange flavor }\end{array}$ & $1,16^{\mathrm{b}}$ & $1,42^{\mathrm{ab}}$ & $2,00^{\mathrm{a}}$ & $1,08^{\mathrm{b}}$ \\
\hline $\begin{array}{l}\text { Maciez } \\
\text { Tenderness }\end{array}$ & 4,17 & 4,08 & 4,17 & 4,25 \\
\hline $\begin{array}{l}\text { Suculência } \\
\text { Juiciness }\end{array}$ & 5,25 & 5,00 & 4,83 & 5,08 \\
\hline $\begin{array}{l}\text { Preferência }{ }^{3} \\
\text { Acceptability }\end{array}$ & $2,08^{b}$ & $2,58^{\mathrm{ab}}$ & $3,33^{\mathrm{a}}$ & $1,92^{\mathrm{b}}$ \\
\hline $\begin{array}{l}\text { Cor característica }{ }^{1} \\
\text { Characteristic color }^{2}\end{array}$ & 6,65 & 6,78 & 6,56 & 6,44 \\
\hline $\begin{array}{l}\text { Aparência geral }{ }^{1} \\
\text { Overall aspect }\end{array}$ & 6,77 & 6,92 & 6,77 & 6,72 \\
\hline
\end{tabular}

Letras diferentes na mesma linha diferem significativamente $(P<0,05)$.

1 Escala não estrutural variando de 0 a $9,0 \mathrm{~cm}$

2 Escala estrutural variando de 0 a 9.

${ }^{3}$ Escala estrutural variando de 1 a 4.

Different letters in the same row are significantly different $(P<.05)$

${ }^{1}$ Non structural scale varying from 0 to $9.0 \mathrm{~cm}$.

2 Structural scale varying from 0 to 9 .

${ }^{3}$ Structural scale varying from 0 to 4 . 
cozida de aves descartadas e mortas, nas características sensoriais de suculência, intensidade de sabor, maciez e aparência geral da carne de peito e de coxa.

\section{Conclusões}

O uso de probiótico não propiciou melhorias nos resultados de desempenho, excetuando-se o rendimento de carcaça e a análise sensorial na característica de preferência, no momento em que o probiótico foi associado ao antibiótico. A suplementação somente do probiótico determinou diminuição dos índices de desempenho (peso, ganho de peso e consumo de ração), indicando que o uso de produtos à base de Enterococcus faecium não é indicado em condições de baixo desafio sanitário.

\section{Referências Bibliográficas}

BERTECHINI, A.G., HOSSAIN, S.M. Utilização de um tipo de probiótico como promotor de crescimento em rações de frangos de corte In: CONFERÊNCIA APINCO 1993 DE CIÊNCIA E TECNOLOGIA AVÍCOLAS, 1993, Santos, 1993. Trabalhos de pesquisa... Campinas: FACTA, 1993, p.1.

BARROW, P.A. 1992. Probiotics for chickens. In: FULLER, R. Probiotics, the scientific basis. London: Chapman \& Hall. 1.ed. p.225-252.

CAVAZZONI, V., ADAMI, A., CASTROVILLI, C. et al. 1993. A preliminary experimentation on broilers with a strain of Bacillus coagulans as probiotic. Microbiologie Aliments Nutrition, 11:457-62.

DILWORTH, B.C., DAY, E.J. 1978. Lactobacillus cultures in broiler diets. Poult. Sci., 57:1101.

ENGLAND, J.A., WATKINS, S.E., SALEH, E. et al. 1996. Effects of Lactobacillus reuteri on live performance and intestinal development of male turkeys. J. Appl. Poult. Res., 5:311-324.

FULLER, R. 1989. Probiotics in man and animals. A review. J. Appl. Bacteriology, 66:365-378.

HENRIQUE, A.P.F., FARIA, D.E., NETO, R.F. et al. Uso de probióticos e antibióticos como promotores de crescimento para frangos de corte. In: CONFERÊNCIA APINCO DE CIÊNCIA E TECNOLOGIA AVÍCOLAS, 1997, São Paulo. Trabalhos de Pesquisas... Campinas: FACTA, 1997. p.27.

INSTITUTE OF FOOD TECHNOLOGISTS. 1981. Sensory evaluation division. Sensory evaluation guide for testing food beverage products. Food Technology, 35:49-58.

JENSEN, J.F., JENSEN, M.M. The effect of using growth promoting Bacillus strains in poultry feed. In: WORLD'S POULTRY CONGRESS, 18, 1992, Amsterdam. Proceedings... Amsterdam: WPSA, 1992, 3, p.398-402.

JERNIGAN, M.A., MILES, R.D. 1985. Probiotics in poultry nutrition. A review. World's Poult. Sci. J., 41:99-107.

JIN, L.Z., HO, Y.W., ABDULLAH, N. et al. 1997. Probiotics in poultry: modes of action. World's Poult. Sci. J., 53:351-368.
JIN, L.Z., HO, Y.W., ABDULLAH, N. et al. 1998. Growth performance, intestinal microbial populations, and serum cholesterol of broilers fed diets containing Lactobacillus cultures. Poult. Sci., 77:1259-1265.

JIRAPHOCAKUL, S., SULLIVAN, T.W., SHAHANI, K.M. 1990. Influence of a dried Bacillus subtilis culture and antibiotics on performance and intestinal microflora in turkey. Poult. Sci., 69:1966-73.

KHAN, M.L., ULLAH, I., JAVED, M.T. 1992. Comparative study of probiotics, T.M. 50 Biovin-40 and Albac on the performance of broiler chicks. Pakistan Vet. J., 12:145-7.

KRINKE, A.L., JAMROZ, D. 1996. Effects of feed antibiotic avoparcine on organ morphology in broiler chickens. Poult. Sci., 75:705-710.

LESSON, S., SUMMERS, J.D., FERGUNSON, A.E. 1980. Efficacy of avoparcin as a growth promoter for broiler chickens. Can. J. Anim. Sci., 60:275-279.

MOHAN, B., KADIRVEL, R., NATARAJAN, A. et al. 1996. Effect of probiotic supplementation on growth, nitrogen utilization and serum cholesterol in broilers. Br. Poult. Sci., 37:395-401.

MERKELY, J.W. 1985. Probiotics supplementation of broiler diets and RTC carcass yield. Poult. Sci., 64(1.1):145.

MULDER, R.W.A.W. 1991. Probiotics as a tool against Salmonella contamination. Misset World Poult., 7:36-37.

OWINGS, W.J., REYNOLDS, D.L., HASIAK, R.J. et al. 1990. Influence of dietary supplementation with Streptococcus faecium M-74 on broiler body weight, feed conversion, carcass characteristics and intestinal microbial colonization. Poult. Sci., 69:1257-64.

ROÇA, R.O., BONASSI, I.A. Seleção de provadores para produtos cárneos. In: CONGRESSO BRASILEIRO DE CIÊNCIA E TECNOLOGIA DE ALIMENTOS, 1985, Itabuna. Anais... Itabuna: SBCTA, 1985, p.83.

SAS ${ }^{\circledR}$ - STATISTICAL ANALYSIS SYSTEM. 1989. Language and procedures. 1.ed., version 6. Cary: SAS Institute. 638p.

SNEDCOR, G.W., COCHRAN, W.G. 1967. Statistical methods. 6.ed. Ames: The Iowa State University Press. p.327-329.

TABELAS da Avicultura. 1995. Aves \& Ovos, 11.

TOURNUT, J.R. Probiotics. In: REUNIÃO DA SOCIEDADE BRASILEIRA DE ZOOTECNIA, 35, 1998, Botucatu. Anais... Botucatu: SBZ, 1998, p.179-199.

WOLKE, L.F., FLEMING, J.S., MIRA, R.T. et al. Utilização do probiótico Bacillus natto como promotor de crescimento na alimentação de frangos de corte. In: REUNIÃO ANUAL DA SOCIEDADE BRASILEIRA DE ZOOTECNIA, 23, 1996, Fortaleza. Anais... Fortaleza: SBZ, 1996, p.36-38.

WATKINS, B.A., KRATZER, F.H. 1984. Drinking water treatment with a commercial preparation of a concentrated Lactobacillus culture for broiler chickens. Poult. Sci., 63:1671-1673.

WILLIAMS, S.K., DAMRON, B.L. 1998. Sensory and objective characteristics of broiler meat from commercial broilers fed rendered whole-hen meal. Poult. Sci., 77:329-333.

Recebido em: 14/07/1999 Aceito em: 17/11/1999 